\title{
Program Committee Chairman
}

\section{A. S. Kurkov}

DOI: $10.1134 / \mathrm{S} 1054660 \mathrm{X} 11040074$

The Fourth Russian Seminar on Fiber Lasers took place in Ul'yanovsk on April 19-22, 2010. The event upholds traditions of the Seminars in Novosibirsk (2007), Saratov (2008), and Ufa (2009) [1]. The Seminar was organized by the Ul'yanovsk State University. Components of fiber lasers, various configurations of fiber lasers and amplifiers, nonlinear phenomena in optical fibers, applications of fiber lasers in communications and technology, and fiber-optic sensors were the Program highlights. More than 100 participants from Novosibirsk, Snezhinsk, Kazan, Samara, Saratov, Ul'yanovsk, Moscow, Fryazino, and other Russian cities presented 70 reports.

Note the invited presentations on femtosecond lasers (Prof. O. Okhotnikov, University of Tampere, Finland), specific optical fibers (S.L. Semenov, FORC, RAS, Moscow), and dynamics of fiber Brillouin mirror (A.A. Fotiadi, University of Mons, Belgium) and the regular presentations on the lasers with frequency doubling (S.F. Babin et al., Novosibirsk), femtosecond lasers (S.M. Kobtsev et al.), and applications in communications (M.P. Fedoruk et al.). Several reports were devoted to the practical applications of fiber lasers. E.L. Surmenko (Saratov State Technical University) characterized the applications of fiber lasers in microelectronic industry and I.S. Shelemba (Institute of Automation and Electrometry, Siberian Branch, Russian Academy of Sciences) presented a practical system for the measurement of the temperature distribution in the stator winding of an industrial turbogenerator.

The scientific results of the Seminar were discussed, and it was decided to organize the next Seminar in Novosibirsk in 2012.

The Seminar was supported by the Russian Foundation for Basic Research (project no. 10-02-06034-g).

\section{REFERENCES}

1. A. S. Kurkov, Laser Phys. 20, 303 (2010). 